\title{
Remote learning during COVID-19: cognitive appraisals and perceptions of english medium of instruction (EMI) students
}

\section{H. Gülru Yüksel ${ }^{1}$ (D)}

Received: 27 January 2021 / Accepted: 13 July 2021 / Published online: 13 August 2021

(c) The Author(s), under exclusive licence to Springer Science+Business Media, LLC, part of Springer Nature 2021

\begin{abstract}
Many countries responded to the Covid-19 pandemic by transforming all face-toface $(\mathrm{F} 2 \mathrm{~F})$ courses to emergency remote teaching with a sudden decision. This rapid shift was unexpected and staggering for the university students. The purpose of the present study is to explore how students studying in English Medium Instructed (EMI) programs cognitively appraised the transformation from F2F to online learning, and to examine if there is any relation between perceived self-efficacy in academic second language (L2) use, quality of interaction, and course satisfaction. Using an online survey, data was collected from a total of 306 graduate and undergraduate students studying in different universities in Turkey. The study found that the majority of the students appraised the transformation as a threat. The students' cognitive appraisals and perceived level of interactional quality, and satisfaction negatively correlated. There was a strong positive correlation between the perceived level of interactional quality and satisfaction. Observed gender, major and year level differences are also reported. The findings have significant implications for decision makers and instructors. Universities are likely to continue remote teaching for a while, thus institutions need to capture how students are affected by the remote learning experience to envisage short and long-term scenarios, and to optimize the quality of their services accordingly.
\end{abstract}

Keywords COVID-19 - Cognitive appraisal · Quality of interaction · Remote online learning $\cdot$ Student satisfaction

H. Gülru Yüksel

hayuksel@yildiz.edu.tr

1 Department of Foreign Languages Education, Faculty of Education, Y1ld1z Technical University, İstanbul 34180, Turkey 


\section{Introduction}

The rapid evolution of the Covid-19 into a health crisis has severely disrupted daily life globally. Governments took immediate measures to control the spread of the infection (Marinoni et al., 2020). According to UNESCO (2020), as of March 2020, 193 countries had taken country-wide closure decisions, disrupting education for 1.5 billion pupils globally. Many countries responded to this health crisis by closing the doors of the universities to students and transforming all face-to-face (F2F) courses to emergency remote teaching. Turkey is among the countries which made similar closure decisions to combat the pandemic. Ministry of National Education announced that all schools would close starting on 16 March 2020. With a directive by the Council of Higher Education (CoHE) (2020), institutions of all sizes and types were mandated to transform all F2F classes to online lessons. This closure affected 24 million students in Turkey, including 7 million university students (UNESCO, 2020).

For many policymakers and educational authorities has seen online teaching as an alternative to sustaining education. Effective online education requires detailed planning, preparation, and development time (Hodges et al., 2020), yet the move to remote online learning due to the COVID-19 pandemic left no room for such design decisions (Bao, 2020; Baber, 2020). This move was unexpected and staggering for instructors and students, and generated discussions over the quality of learning (Baber, 2020).

Quality in higher education is a multidimensional phenomenon. Since different stakeholders approach quality in education from different lenses, there is no consensus on its definition and measurement (Harvey, L. and Green 1993). In the literature, research investigating student perspective defines quality in higher education as "the difference between what a student expects to receive and his/her perceptions of actual delivery" (O'Neill \& Palmer 2004, p. 42). Within this frame, students' perceptions of their learning experience and satisfaction often serve as a proxy for the success and quality of online learning (Bolliger \& Wasilik, 2009; Jiang et al., 2021). Prior to the massive lockdown, several studies comparing F2F and online learning have considered student satisfaction as a key performance indicator (Moore \& Kearsley, 2005).

Several factors have been found to contribute to satisfaction such as interaction, self-efficacy, prior experience and course design (cf. Lee, 2010; Lee et al., 2007; Liaw \& Huang, 2013; Eom, 2009; Jan, 2015; Kuo et al., 2014; Swan, 2001). In the current situation, however, students' psychological responses to the change may also influence their satisfaction. Therefore, the primary purpose of the present study is to explore how students enrolled in English as a medium of instruction (EMI) programs cognitively appraised the transformation from F2F to online learning, and to examine if there is any relation between perceived self-efficacy in academic second language (L2) use, quality of interaction, and course satisfaction. 


\section{Background}

Astin (1993) defines student satisfaction as the perceived value of educational experiences at an educational institution (as cited in Bolliger \& Martindale, 2004, p. 104). Student satisfaction is an attitudinal construct that is dependent on personal experiences and beliefs (Dominici \& Palumbo, 2013; Lee, 2010; Kuo et al., 2014). In the literature, student satisfaction is found to relate to program quality (Debourgh, 1999; Moore \& Kearsley, 2005; Yükseltürk \& Yıldırım, 2008), motivation (Y1lmaz, 2017), drop-out rates and retention (Lee \& Choi, 2013; Reinhart \& Schneider, 2001), and student performance (Biner et al., 1997).

Adopting multiple approaches, several researchers have investigated student satisfaction in online settings over the past decade. Self-efficacy and interaction are among factors that have frequently been reported to be related to student satisfaction. Self-efficacy refers to the beliefs of a person concerning his/ her ability to perform a certain task. The level of self-efficacy influences one's performance and success in many ways because it interacts both with the cognitive and affective processes (Bandura, 1994). Self-efficacy has been rigorously investigated in traditional F2F instructional settings and was found to be related to performance (Coutinho, 2008), engagement (Muenks et al., 2017), achievement (i.e., Cassidy, 2012; Richardson et al., 2012; Schunk, 1989), and satisfaction (Dewitz \& Walsh, 2002).

In online learning context, past research exploring the relationship between self-efficacy and satisfaction have primarily concentrated on the technical dimension of self-efficacy, such as Internet self-efficacy (Liang \& Tsai, 2008; Kuo et al., 2014), computer self-efficacy (Jan, 2015; Johnson et al., 2008; Lim, 2001), and learning management system self-efficacy (Martinet al., 2010). However, in a recent study Alzahrani and Seth (2021) analyzed factors influencing students' satisfaction with their continuing use of online learning management systems in higher education during the COVID-19 pandemic. The findings revealed that self-efficacy had substantial effects on satisfaction.

Interaction is considered as another important factor influencing student satisfaction (Bolliger \& Martindale, 2004). Adapting Moore's (1989) model of interaction, which distinguishes three types of interaction in online education as learner-learner, learner-instructor and learner-content interaction, many researchers have explored the relation between interaction and student satisfaction in different contexts (Bolliger \& Martindale, 2004; Bray, Aoki and Dlugosh 2008; Eom, 2009; Şahin, 2007; Yükseltürk \& Yıldırım, 2008). However, no consensus has been reached as to which type of interaction is more influential. While some studies report learner-instructor interaction as a significant predictor (i.e., Bolliger \& Martindale, 2004; Swan, 2001; Yükseltürk \& Yıldırım, 2008), some other studies find learner-content interaction as an important predictor of satisfaction (i.e., Kuo et al., 2014). In a recent study, however, Alqurashi (2019) reports that all three types of interaction significantly predicts satisfaction. Although interaction among learners is seen essential in creating learning community and increasing engagement (Joksimovic et al., 2015), learner-learner interaction is not seen 
as imperative in online learning environment. The variation in findings might result from the quality rather than the type of interaction. In a study synthesizing research on students' perceptions of online courses, Young and Norgard (2006) assert that the quality interaction is important for student satisfaction.

In a recent study, Karadağ and Yücel (2020) investigated the satisfaction levels of 17,939 Turkish students from 163 universities regarding the remote online education during the Covid-19 pandemic. The results revealed that the overall satisfaction of the students ranged between 3.73 and 2.63 out of 5. There was no statistically significant difference in satisfaction level by gender, university type, or grade level. Furthermore, the students were found to be dissatisfied with the instructional materials, the teaching competences of the instructors, and the level of interaction with the instructors.

Perceptions related to the quality of interaction may also be related to the language of instruction. Social constructivist theory of learning posits that learning is interactive, discursive, and situated (Lapadat, 2002). This precept turns language into an important mediator of learning. While effective use of language facilitates learning, its ineffective use might lead to misunderstandings, and hence, hinder learning (Palincsar, 1998). Given the importance of language of instruction in learning, the learning experiences of EMI students should also be taken into account. However, there is little research on the satisfaction of EMI students in online learning environments. Most recently, Kamal et al. (2021) examined the impact of distance education on English language learning during the coronavirus pandemic. Researchers compared students' cognitive abilities (concentration and memory) and academic performance in three conditions (F2F; distance learning and distance learning during pandemic). They found decrease in all variables studied in the distance learning during the pandemic. This suggests that the students' psychological condition may potentially affect their perceptions.

It is a well-known fact that traumatic incidents and emergency situations create stress in individuals (Peacock \& Wong, 1990), and results in the arousal of negative feelings. The Covid-19 pandemic is one of the most traumatizing events in recent years. Since its outbreak, this mass trauma is having substantial effect on society, including mental health and physical health (Holmes et al., 2020). The results of a survey study by Cao et al. (2020) revealed that about $25 \%$ of the university students experience mild to severe anxiety resulting from Covid-19. In another study, Hasan and Bao (2020) studied the psychological effects of covid-19 "e-learning crack-up" and found that "e-Learning crack-up" perception has influence on student's psychological distress. The authors concluded that fear of academic year loss is the primary cause of psychological distress during Covid-19 lockdown. Similarly, Cleofas and Rocha (2021) explored covid-19 related anxiety among Filipino college students and found that majority of the students had high levels of anxiety.

Individuals, who encounter such stressful experiences, undergo a specific cognitive appraisal process (Folkman \& Lazarus, 1984). Cognitive appraisals are seen as important indicators of stress responses under emergency conditions (Harvey et al., 2010). According to cognitive appraisal theory, individuals under stress conditions subjectively appraise the demands of the situation (primary appraisal) and subsequently decide if they have sufficient resources to meet these demands (secondary 
appraisal) (Folkman et al., 1986). When the person determines that his/her resources are adequate to cope with the situation, the situation is appraised as a challenge (Matthieu \& Ivanoff, 2006; O'Connor et al., 2010). On the contrary, if the resources are inadequate, the situation will be appraised as a threat (Harvey et al., 2010). In the current emergency situation, students' cognitive appraisals may interact with their satisfaction, perceptions of quality of interaction and self-efficacy in academic L2 use.

The study was guided by the following research questions:

1. How do EMI students cognitively appraise the transformation from $\mathrm{F} 2 \mathrm{~F}$ to online learning?

2. To what extent does students' cognitive appraisal (CA) correlate with their selfefficacy in academic L2 use (SEAL2), perceived quality of interaction (PQI), and satisfaction (SAT) with online learning as compared to face-to-face (F2F) learning?

3. Do the independent variables vary according to gender, major, year level, prior experience and course type?

\section{The study}

This study is an exploratory quantitative study by design. Data were collected during the first wave of pandemic prior to the administration of the final exams. Online survey method was used to collect data.

\subsection{Participants}

The participants recruited using snowball technique. An initial call for participation was emailed to potential participants and they were requested to share the link of an online survey with other student. A total of 306 students from different universities in Turkey responded the survey. The participants took part in the study voluntarily and no identifying information was collected on the survey. All of the participants were EMI students from different universities with various educational backgrounds (undergraduate, graduate) and online learning experience responded to an online survey. About $60 \%$ of them were female and $40 \%$ were male students. Of the 306 participants, $94(30.7 \%)$ were freshmen, 46 (15\%) were sophomores, $85(27.8 \%)$ were juniors, 85 (27.8\%) were seniors, and 37 (12\%) were graduates. Regarding their academic background, $44.4 \%$ of the participants were from Social Sciences, $39.5 \%$ were from Science and Engineering, 9.2\% from Humanities, and 5.2\% were form Medicine. As for the previous online learning experience, while about $41 \%$ of them did not take any online course, $23 \%$ of them had taken 1 or 2 courses and $36 \%$ had taken 3 or more online courses. During data collection, $39.9 \%$ of the participants were following live courses, $8.8 \%$ were following video courses and $54.2 \%$ were following both live and video courses (Table 1). 
Table 1 Demographic profile of the students

\begin{tabular}{llll}
\hline Variable & & N of students (N=306) & Percent \\
\hline Gender & Female & 184 & 60.1 \\
& Male & 122 & 39.9 \\
University & State & 256 & 83.7 \\
Major & Private & 44 & 14.4 \\
& Social Sciences (SOC) & 136 & 44.4 \\
& Science and Engineering (SCIE) & 121 & 39.5 \\
& Humanities (HUM) & 28 & 9.2 \\
Year & Medicine (MED) & 16 & 5.2 \\
& Freshman & 94 & 30.7 \\
& Sophomore & 46 & 15 \\
& Junior & 44 & 14.4 \\
Experience & Senior & 85 & 27.8 \\
& Graduate & 37 & 12 \\
& None & 126 & 41.2 \\
Course type & 1 or 2 online courses & 69 & 22.5 \\
& 3 or more online courses & 111 & 36.3 \\
& Synchronous & 113 & 36.9 \\
& Asynchronous & 27 & 8.8 \\
& Both & 166 & 54.2 \\
\hline
\end{tabular}

Data have been anonymized and no participant is identifiable in this paper. All the participants were informed about the aim of the study on the first section of the survey and they were requested to waive informed consent by clicking on a button.

\subsection{Data collection instrument}

The researcher created an online survey based on related literature. The survey includes the following sections:

1) Demographic information (7 items): The part is to collect information about learner characteristics (gender, type of university, major, year, prior experience in taking online courses and the type of online course offered during the semester).

2) Cognitive appraisal (CA) (5 items): Cognitive appraisal (CA) was assessed using the method described by Harvey et al. (2010). The section comprised of 3 questions for primary appraisal ('How demanding is the change from F2F to online courses?', 'How demanding are the assignments?' and 'How demanding is the overall workload?') and 2 questions for secondary appraisal ('How able are you to cope with this change?' and 'To what extent do you think this change will have positive impact on your performance?'). After calculating the average scores, an index of cognitive appraisal was calculated by the taking ratio of the primary to secondary appraisal. An index equal to or less than 1 indicates that 
the situation is appraised as a 'challenge' (ratio $\leq 1$ ), while an index greater than 1 indicates that the situation is appraised as a 'threat' (ratio $>1$ ) (Harvey et al., 2010).

3) The third section comprised of three subscales (14 items). The self-efficacy in academic L2 use subscale was developed by the researcher. The items were pooled from The Global Scale of English (GSE) Teacher Toolkit and stated in accordance with Bandura's (2006) guideline. It consisted of six items, asking students to rate their confidence in using L2 on a 7-point scale ranging from 1 (cannot do at all) to 7 (highly certainly can do). The students' perceptions of interactional quality and satisfaction with their remote online learning experience as compared to F2F learning subscales consisted of 8 items in total. The perceptions of interactional quality items were adapted from scales developed by Otter et al., (2013) and $\mathrm{Ni}$ (2013). Participants were asked to rate their perceptions on a 7-point scale ( $1=$ poor quality, $7=$ high quality). The satisfaction items were adapted from Kuo et al. (2014). Participants responded to the items on a 7-point scale ( $1=$ not satisfied at all, $7=$ extremely satisfied).

\subsection{Data analysis}

The data analysis involved the following statistical procedures. Demographic characteristics of the participants and study variables were analyzed descriptively (Table 1). To identify clusters of inter-correlated variables, an explanatory factor analysis (EFA) using principal-components analysis and oblique rotation was performed. Graphical and statistical analysis indicated a non-normal distribution around the mean for all variables, showing violation of the assumptions for a parametric test. Homogeneity of variances was tested using the recently developed non-parametric Levene's test (Nordstokke \& Zumbo, 2010; Nordstokke et al., 2011). The test showed statistically significant differences between variances for all variables and groups $(\mathrm{p}<0.05)$. Hence, based on these descriptive explorations of data, the Mann-Whitney $U$ test and Kruskal Wallis test were adopted for group comparisons. The correlations between variables were examined using the Spearman's correlation test Table 1.

\section{Findings}

\subsection{Explanatory factor analysis}

Initially, the factorability of the 14 items was examined. The results from the Kaiser-Meyer-Olkin measure of sampling adequacy (KMO) (0.857) and Bartlett's test of Sphericity $(\chi 2(91)=2276.585, \mathrm{p}<0.001)$ indicated that the data set was suitable for factor analysis. Initial Eigen values indicated a three-factor solution accounting for $66.54 \%$ of the total variance. Internal consistency was assessed using Cronbach's alpha was 0.86 for the whole scale. The first factor, perceptions of interactional quality (PQI) included five items $(\alpha=0.83)$. The second factor, self-efficacy in academic 


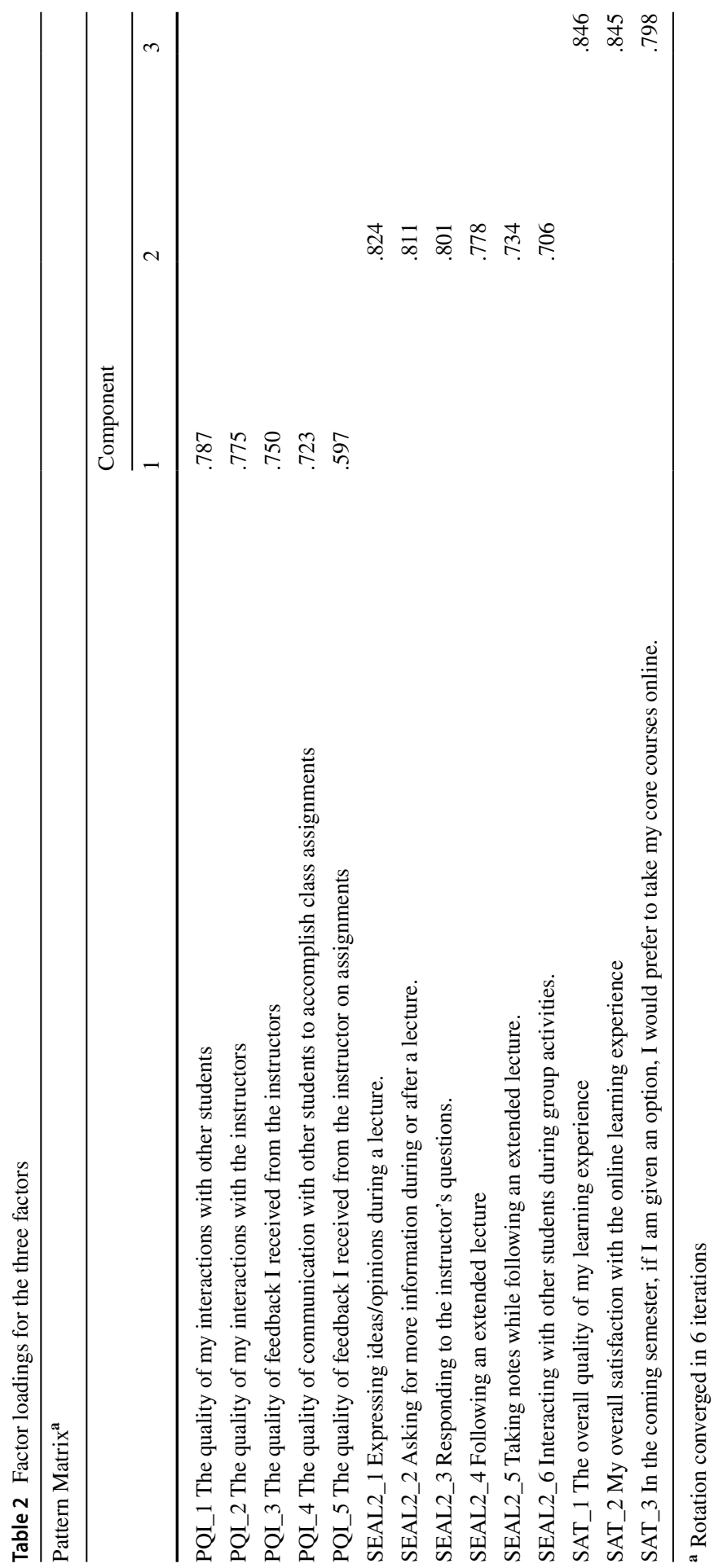


L2 use (SEAL2) included six items $(\alpha=0.87)$. The third factor, satisfaction (SAT) included three items $(\alpha=0.88)$. Table 2 displays the factor loadings after rotation.

\subsection{Students' cognitive appraisals}

Overall, the CA index calculated showed that 82 of the 306 respondents $(26.8 \%)$ appraised the transformation from F2F to online learning as a challenge $(M=0.86$, $\mathrm{SD}=0.016)$. The remaining 224 students (73.2\%) appraised the change as a threat $(\mathrm{M}=2.65, \mathrm{SD}=0.105)$. This result indicated that due to the shift the majority of the EMI students cognitively assessed that their resources were insufficient to meet the task demands, resulting in a high level of stress. similar

\subsection{Relation between CA, SEAL2, PQI, and SAT}

The second question sought possible relations between $\mathrm{CA}$ and other variables (namely, SEAL2, PQI and SAT). To this end, a series of Spearman's rank-order correlation was run. Table 3 displays the means, standard deviations and Spearman correlations among variables. The highest mean score was measured for the SEAL2 $(\mathrm{M}=4.42, \mathrm{SD}=1.45)$. Although the SEAL2 mean was higher than the mid-point of the scale, it indicated a medium level of self-efficacy in academic L2 use. Regarding the PQI, the mean score indicated that students perceived the quality of interaction in online courses as low $(\mathrm{M}=3.43, \mathrm{SD}=1.33)$. The lowest mean score was measured in the overall satisfaction with the remote online learning as compared to F2F learning $(\mathrm{M}=3.28, \mathrm{SD}=1.65)$.

The Spearman's rho yielded a statistically significant negative correlation between the CA and PQI $\left(\mathrm{r}_{\mathrm{s}}[306]=-0.308, \mathrm{p}<0.000\right)$ and between CA and SAT and $\left(r_{s}[306]=-0.609, p<0.000\right)$. There was not significant correlation between CA and SEAL2. While the effect size of the relationship between CA and PQI was moderate, the effect size of the relationship between CA and SAT was strong (Frey, 2018). Squaring the correlation coefficients indicated that $10 \%$ of the variance in the PQI, and $25.6 \%$ of the variance in the SAT was explained by the CA.

In terms of the relationship among other variables, the Spearman's rho revealed a statistically significant positive relationship between the SEAL2 and PQI, $\left(\mathrm{r}_{\mathrm{s}}[306]=0.244, \mathrm{p}<0.000\right)$. However, the correlation was weak, which explained only $6 \%$ of the variance in the dependent variable. Also, there was a significant relationship between the SEAL2 and SAT $\left(\mathrm{r}_{\mathrm{s}}[306]=0.186, \mathrm{p}<0.001\right)$. However, the

Table 3 Means, standard deviations, and Spearman correlations among the study variables

\begin{tabular}{lllllll}
\hline & $\mathrm{M}$ & $\mathrm{SD}$ & 1 & 2 & 3 & 4 \\
\hline 1 CA & 1.65 & 1.13 & - & & & \\
2 SEAL2 & 4.42 & 1.45 & -.088 & - & & \\
3 PQI & 3.43 & 1.33 & $-.308^{* *}$ & $.244^{* *}$ & - & \\
4 SAT & 3.28 & 1.65 & $-.609^{* *}$ & $.186^{* *}$ & $.561^{* *}$ & - \\
\hline
\end{tabular}

** Correlation is significant at the 0.01 level (2-tailed) 
relationship was very weak, explaining the $3 \%$ of the variance. A significant positive correlation was found between the PQI and SAT $\left(\mathrm{r}_{\mathrm{s}}[306]=0.561, \mathrm{p}<0.000\right)$. The effect size of the correlation was strong (Frey, 2018). The effect explained the $31.5 \%$ of the variance in the dependent variable. Figure 1 below illustrates the relation among variables.

\subsection{Differences in variables}

This study also explored whether the variables differ according to gender, major, year level, prior experience, and course type. As for the gender differences, the Mann-Whitney $U$ tests showed significant differences in the SEAL2, PQI and SAT measures. While the self-rated SEAL2 of the females was significantly higher than that of the males $(\mathrm{U}=8956.500, \mathrm{z}=-2.99, p=0.003)$, the PQI and SAT of the males were statistically significantly higher than that of the females $(U=9725, z=-1.98$, $p=0.048$, and $\mathrm{U}=9588, \mathrm{z}=-2.16, p=0.03$, respectively). The CA did not significantly differ by genders.

With respect to major, except for the SEAL2 score, no statistically significant differences were observed between groups. A Kruskal-Wallis $\mathrm{H}$ test revealed that there was a statistically significant difference in SEAL2 scores between different majors, $\chi^{2}(3)=22.226, p=0.000$, with a mean rank SEAL2 score of 173.18 for Social Sciences, 125.35 for Science and Engineering, 169.64 for Humanities and 123.78 for Medicine. Post-hoc Mann-Whitney U tests using Bonferroni adjusted alpha level of 0.013 was used to compare all pairs of groups. Only the difference in SEAL2 between Social Sciences and Science and Engineering was found to be statistically significant $(\mathrm{U}=5571, \mathrm{z}=-4.470, p=0.000)$. The self-rated SEAL2 was greater for the students of Social Sciences $(M=3.40)$ than for the students of Science and Engineering $(\mathrm{M}=3.15)$.

Similarly, differences among year levels were evaluated using a Kruskal-Wallis H test. The test indicated statistically significant differences in SEAL2 scores between different year levels $\left(\chi^{2}(4)=17.219, p=0.002\right)$. Post-hoc Mann-Whitney tests showed significant difference in SEAL2 between freshman and graduate, and sophomore and graduate were statistically significant $(\mathrm{U}=493, \mathrm{z}=-3.285, p=0.002$, and $\mathrm{U}=1026$, $\mathrm{Z}=-3.649, p=0.008$, respectively). Furthermore, significant differences were found

Figure 1. Relation between SAT, CA, PQI and SEAL2

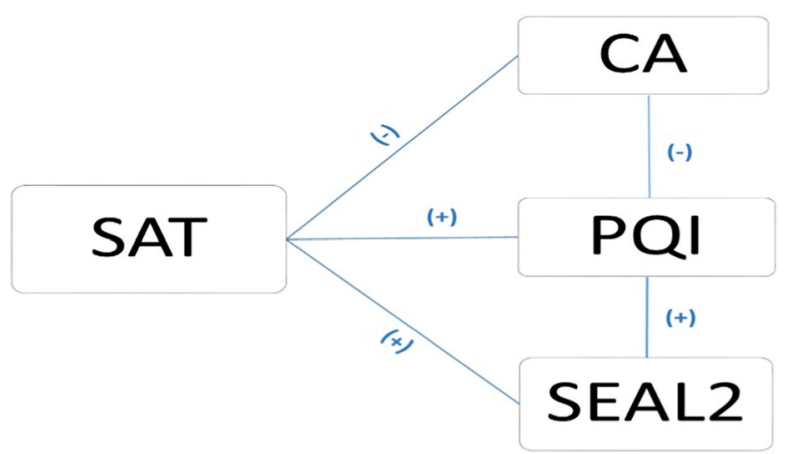


in the SAT scores $\left(\chi^{2}(4)=17.048, p=0.002\right)$. Post-hoc Mann-Whitney tests indicated significant differences in SAT scores across year levels. There were significant differences in satisfaction between freshman and graduate $(\mathrm{U}=1037.5, \mathrm{z}=-3.596$, $p=0.005)$, between sophomore and graduate $(\mathrm{U}=487.5, \mathrm{z}=-3.339, p=0.002)$, and between junior and graduate $(\mathrm{U}=490.5, \mathrm{z}=-3.081, p=0.02)$ level of students.

Regarding the differences in subscales across prior experience and course type, none of the other comparisons were significant.

\section{Discussion}

The study reported here explored how EMI students cognitively appraised the transition from F2F to remote online learning caused by the COVID-19 pandemic, and to what extent their appraisals interacted with their self-efficacy in academic L2 use, perceptions of quality of interaction and satisfaction. The findings from the CA index indicated that the majority of the students appraised this change as threat. This finding echoes previous studies from different contexts that have reported psychological distress among college students (Hasan \& Bao, 2020; Kapasia et al., 2020).

Student satisfaction in remote online learning is influenced by a variety of interrelated attitudinal factors. Self-efficacy in academic L2 use is one such factor notably for students who pursue their education in a second language. Data from this study showed that the EMI students exhibited a medium level of self-efficacy in academic L2 use. This level was not as high as expected when compulsory preparatory year is taken into account. Similarly, Genç et al. (2016) found that Turkish learners of English as a foreign language had a medium level of English self-efficacy. This finding indicated not only a compelling need to reconsider the proficiency criteria for EMI programs, but also a need to provide further language assistance in academic language use. In a recent study investigating the perceptions of EMI students, Ekoç (2020) found that only a few students passed the proficiency exam with a score above the threshold score and that the majority of students were not content with the instruction they received during the preparatory year. These findings led the researcher to conclude that alterations per language proficiency levels are required.

As for the perceptions of the quality of interaction in online classes, the overall mean calculated was lower than the self-efficacy in academic L2 use level. This might be due partly to their confidence in their abilities in academic L2 use, and partly their threat appraisals. Indeed, significant positive correlation between selfefficacy in L2 use and perceptions of quality of interaction, and negative correlation between perceptions of quality of interaction and cognitive appraisals lend support to this observation. This finding is consistent with Shea and Bidjerano's (2010) study, which explored the relationship between learner self-efficacy measures and their ratings of the quality of their learning in virtual environments. The researchers showed a positive correlation between students' self-efficacy and their perceptions of the quality of online learning experiences.

In the present study, as with the perceived quality of interaction, EMI students' satisfaction with the remote online learning was low. Indeed, of the variables under examination, satisfaction had the lowest mean score. The finding that the 
mean value was lower than the midpoint of the scale suggested that EMI students were not satisfied with their remote learning experiences. Furthermore, we found a significant correlation between satisfaction and perceived quality of interaction. Taken together, these findings revealed that interactional quality is one of the factors influencing satisfaction. Previous research has yielded similar results (Young \& Norgard, 2006; Kuo et al., 2014; Alqurashi, 2019).

There are several other findings from correlation analysis worth to discuss. First, there was a negative correlation between the students' cognitive appraisals and perceived level of interactional quality and satisfaction. While the correlation between the cognitive appraisal and interactional quality was moderate, the correlation between cognitive appraisal and satisfaction was strong. These findings indicated that students' psychological state is an influential factor on the satisfaction with remote online learning. Secondly, the strongest correlation was found between perceived quality of interaction and satisfaction. This finding echoes the results of previous research (i.e., Bolliger \& Martindale, 2004; Bray et al., 2008; Eom, 2009; Şahin, 2007; Yükseltürk \& Yıldırım, 2008), and affirms the impact of the quality of interaction in online courses on satisfaction. In the present study, a low but statistically significant correlation was found between the self-efficacy in academic L2 use and perceived quality of interaction. This finding suggests that while most students possessed a sufficient level of ability in using their L2 for academic purposes, some others might need support to improve their interactional L2 skills.

In terms of the differences in variables, regardless of independent variable (gender, major, year level, prior experience, and course type), no significant differences were found in the students' cognitive appraisals. This result suggested that the Covid-19 crisis has caused the arousal of negative emotional responses in the majority of students, which might possibly influence their perceptions. Under such emergency conditions, instructors should take students' psychological states into account while making design and assessment decisions. In the self-reported SEAL2, significant differences were observed between genders, majors, and year levels. Females exhibited higher self-efficacy in academic L2 use as compared to males. Past research findings on self-efficacy have also reported gender differences in favor of females. For example, in a recent study, Jan (2015) found that females had higher academic self-efficacy than males. The observed variation in SEAL2 between students of Social Sciences and of Science and Engineering indicated an advantage of the major. Similarly, the graduates had higher SEAL2 levels than both the freshmen and sophomores. These findings provide evidence that self-efficacy beliefs are formed over time through experience.

As for the satisfaction variable, we found that males were more satisfies with the remote online learning than females. This finding is in line with previous studies. Similar to our findings, Umbach and Porter (2002) reported that females had lower satisfaction with online classes than do males. In addition, in this study, significant differences in satisfaction were found between year levels. Graduates had higher satisfaction than freshmen, sophomores and juniors. This finding indicated that prior experience plays an important role in improving student satisfaction levels. Since graduate students had more chances to take 
online courses during their undergraduate studies, these prior experiences may have positively contributed to their course satisfaction.

\section{Conclusion and implications}

Because the COVID-19 quickly escalated into a public health emergency, colleges made a sudden decision to continue teaching online. The present study explored how EMI students cognitively appraised this rapid transformation, and to what extent students' cognitive appraisals correlate with their self-efficacy in academic L2 use, perceived quality of interaction, and satisfaction with remote online learning as compared to face-to-face learning. The results revealed that about $73 \%$ of EMI students appraised the rapid transformation to remote online learning as a treat. The high prevalence of threat appraisal had a detrimental influence on EMI students' perceptions and overall course satisfaction. The findings have significant implications for decision makers and instructors. Universities are likely to continue remote teaching for a while, thus institutions need to capture how students are affected by the remote learning experience to envisage short and longterm scenarios, and to optimize the quality of their services accordingly. Institutions should give systematic training to the instructors on both technological and pedagogical aspects of online learning. Unlike learning under normal conditions, students' emotional responses may adversely affect their beliefs in their abilities in emergency situations, which may result in dissatisfaction with remote online learning, and may ultimately influence students' perceptions and satisfaction. Institutions should monitor not only students' learning and development, but also their psychological conditions in order to provide them guidance and timely psychological assistance. Instructors, on the other hand, must recognize that some students may struggle to balance conflicting academic demands. It is more likely that EMI students who appraised a threat would be less satisfied with their online learning experience. Therefore, instructors may seek ways to increase the quality of interaction to ensure student satisfaction in the coming semesters. To this end, they could create personal and extended interaction opportunities for students.

This study has certain limitations that need to be addressed. First, the study is exploratory in nature and the data collected from students through a self-reported survey. Therefore, the sample cannot be considered representative of all university students enrolled in EMI programs, and caution must be taken when generalizing the findings for the entire population. This study can serve as a test of considering cognitive appraisal (CA) as a variable in future research. In future research on online learning environments, researchers could consider collecting data related to the students' psychological states. Further research with a larger sample can be conducted for a systematic examination of the impact of cognitive appraisal on other variables.

Data availability The anonymized data used in the current study are available from the corresponding author upon request. 


\section{Declarations}

Ethics approval and consent to participation Ethical approval was received from Y1ldiz Technical University Research Ethics Committee. The participants were informed about the aim of the study on the first section of the online survey, and they were requested to waive informed consent by clicking on a button. Data have been anonymized and no participant is identifiable in this paper.

\section{References}

Alqurashi, E. (2019). Predicting student satisfaction and perceived learning within online learning environments. Distance Education. https://doi.org/10.1080/01587919.2018.1553562.

Alzahrani, L., \& Seth, K. P. (2021). Factors influencing students' satisfaction with continuous use of learning management systems during the COVID-19 pandemic: An empirical study. Education and Information Technologies. https://doi.org/10.1007/s10639-021-10492-5.

Baber, H. (2020). Determinants of students' perceived learning outcome and satisfaction in online learning during the pandemic of COVID-19. Journal of Education and e-Learning Research, 7(3), $285-292$.

Bandura, A. (1994). Self-efficacy. In V. S. Ramachaudran (Ed.), Encyclopedia of human behavior (Vol. 4, pp. 71-81). Academic Press. (Reprinted in H. Friedman [Ed.], Encyclopedia of mental health. San Diego: Academic Press, 1998).

Bandura, A. (2006). Guide for constructing self-efficacy scales. In: Pajares, F. \& Urdan, T.S. (Eds.), SelfEfficacy beliefs of adolescents, (pp. 307-337). Greenwich, CT: Information Age Publishing.

Bao, W. (2020). COVID-19 and online teaching in higher education: A case study of Peking University. Human Behavior and Emerging Technologies. https://doi.org/10.1002/hbe2.191.

Biner, P. M., Welsh, K. D., Barone, N. M., Summers, M., \& Dean, R. S. (1997). The impact of remotesite group size on student satisfaction and relative performance in interactive telecourses. American Journal of Distance Education. https://doi.org/10.1080/08923649709526949.

Bolliger, D. U., \& Martindale, T. (2004). Key factors for determining student satisfaction in online courses. International Journal on E-learning, 3(1), 61-67.

Bolliger, D. U., \& Wasilik, O. (2009). Factors influencing faculty satisfaction with online teaching and learning in higher education. Distance Education. https://doi.org/10.1080/01587910902845949.

Bray, E., Aoki, K., \& Dlugosh, L. (2008). Predictors of learning satisfaction in Japanese online distance learners. International Review of Research in Open and Distributed Learning. https://doi.org/10. 19173/irrodl.v9i3.525.

Cao, W., Fang, Z., Hou, G., Han, M., Xu, X., Dong, J., \& Zheng, J. (2020). The psychological impact of the COVID-19 epidemic on college students in China. Psychiatry Research. https://doi.org/10. 1016/j.psychres.2020.112934.

Cassidy, S. (2012). Exploring individual differences as determining factors in student academic achievement in higher education. Studies in Higher Education. https://doi.org/10.1080/03075079.2010. 545948.

Cleofas, J. V., \& Rocha, I. C. N. (2021). Demographic, gadget and internet profiles as determinants of disease and consequence related COVID-19 anxiety among Filipino college students. Education and Information Technologies. https://doi.org/10.1007/s10639-021-10529-9.

Council of Higher Education (CoHE). (2020). https://covid19.yok.gov.tr/Sayfalar/HaberDuyuru/opinionturkish-higher-education-in-days-of-pandemic.aspx. Accessed 20 June 2020.

Coutinho, S. (2008). Self-efficacy, metacognition, and performance. North American Journal of Psychology, 10(1), 165-172.

Debourgh, G. A. (1999). Technology is the tool, teaching is the task: Student satisfaction in distance learning. In Society for Information Technology \& Teacher Education International Conference (pp. 131-137). Association for the Advancement of Computing in Education (AACE). Retrieved from. https://www.learntechlib.org/p/7521/. Accessed 8 Dec 2019.

Dewitz, S. J., \& Walsh, W. B. (2002). Self-efficacy and college student satisfaction. Journal of Career Assessment. https://doi.org/10.1177/10672702010003003. 
Dominici, G., \& Palumbo, F. (2013). How to build an e-learning product: Factors for student/customer satisfaction. Business Horizons. https://doi.org/10.1016/j.bushor.2012.09.011.

Ekoç, A. (2020). English Medium Instruction (EMI) from the perspectives of students at a technical university in Turkey. Journal of Further and Higher Education. https://doi.org/10.1080/0309877X. 2018.1527025 .

Eom, S. (2009). Effects of interaction on students' perceived learning satisfaction in university online education: An empirical investigation. International Journal of Global Management Studies, 1(2), $60-74$.

Folkman, S., \& Lazarus, R. S. (1984). Stress, appraisal, and coping. Springer Publishing Company.

Folkman, S., Lazarus, R. S., Gruen, R. J., \& DeLongis, A. (1986). Appraisal, coping, health status, and psychological symptoms. Journal of Personality and Social Psychology, 50(3), 571-579.

Frey, B. B. (Ed.). (2018). The SAGE Encyclopedia of Educational Research, Measurement, and Evaluation. Sage Publications. https://doi.org/10.4135/9781506326139.n224.

Genç, G., Kuluşaklı, E., \& Aydın, S. (2016). Exploring EFL learners' perceived self-efficacy and beliefs on English language learning. Australian Journal of Teacher Education. https://doi.org/10.14221/ ajte.2016v41n2.4.

Harvey, A., Nathens, A. B., Bandiera, G., \& LeBlanc, V. R. (2010). Threat and challenge: cognitive appraisal and stress responses in simulated trauma resuscitations. Medical Education. https://doi. org/10.1111/j.1365-2923.2010.03634.x.

Hasan, N., \& Bao, Y. (2020). Impact of "e-Learning crack-up" perception on psychological distress among college students during COVID-19 pandemic: A mediating role of "fear of academic year loss." Children and Youth Services Review. https://doi.org/10.1016/j.childyouth.2020.105355.

Hodges, C., Moore, S., Lockee, B., Trust, T., \& Bond, A. (2020). The difference between emergency remote teaching and online learning. Educause Review, 27, 1-15.

Holmes, E. A., O’Connor, R. C., Perry, V. H., Tracey, I., Wessely, S., Arseneault, L., \& Bullmore, E. (2020). Multidisciplinary research priorities for the COVID-19 pandemic: a call for action for mental health science. The Lancet Psychiatry. https://doi.org/10.1016/S2215-0366(20)30168-1.

Jan, S. K. (2015). The relationships between academic self-efficacy, computer self-efficacy, prior experience, and satisfaction with online learning. American Journal of Distance Education. https://doi. org/10.1080/08923647.2015.994366.

Jiang, H., Islam, A. A., Gu, X., \& Spector, J. M. (2021). Online learning satisfaction in higher education during the COVID-19 pandemic: A regional comparison between Eastern and Western Chinese universities. Education and Information Technologies. https://doi.org/10.1007/s10639-021-10519-x.

Johnson, R. D., Hornik, S., \& Salas, E. (2008). An empirical examination of factors contributing to the creation of successful e-learning environments. International Journal of Human-Computer Studies. https://doi.org/10.1016/j.ijhcs.2007.11.003.

Joksimovic, S., Gaševic, D., Kovanovic, V., Riecke, B. E., \& Hatala, M. (2015). Social presence in online discussions as a process predictor of academic performance. Journal of Computer Assisted Learning. https://doi.org/10.1111/jcal.12107.

Kamal, M. I., Zubanova, S., Isaeva, A., \& Movchun, V. (2021). Distance learning impact on the English language teaching during COVID-19. Education and Information Technologies. https://doi.org/10. 1007/s10639-021-10588-y.

Kapasia, N., Paul, P., Roy, A., Saha, J., Zaveri, A., Mallick, R., Barman, B., Das, P., \& Chouhan, P. (2020). Impact of lockdown on learning status of undergraduate and postgraduate students during COVID-19 pandemic in West Bengal. Children and Youth Services Review. https://doi.org/10. 1016/j.childyouth.2020.105194.

Karadağ, E., \& Yücel, C. (2020). Yeni tip Koronavirüs pandemisi döneminde üniversitelerde uzaktan eğitim: Lisans öğrencileri kapsamında bir değerlendirme çalışması [Distance education at universities during the novel Coronavirus pandemic: An analysis of undergraduate students' perceptions]. Journal of Higher Education (Turkey). https://doi.org/10.2399/yod.20.730688.

Kuo, Y. C., Walker, A. E., Schroder, K. E. E., \& Belland, B. R. (2014). Interaction, internet self-efficacy, and self-regulated learning as predictors of student satisfaction in online education courses. The Internet and Higher Education. https://doi.org/10.1016/j.iheduc.2013.10.001.

Lapadat, J. C. (2002). Written interaction: A key component in online learning. Journal of ComputerMediated Communication. https://doi.org/10.1111/j.1083-6101.2002.tb00158.x.

Lee, J. W. (2010). Online support service quality, online learning acceptance, and student satisfaction. The Internet and Higher Education. https://doi.org/10.1016/j.iheduc.2010.08.002. 
Lee, Y., \& Choi, J. (2013). A structural equation model of predictors of online learning retention. The Internet and Higher Education. https://doi.org/10.1016/j.iheduc.2012.01.005.

Lee, Y. K., Tseng, S. P., Liu, F. J., \& Liu, S. C. (2007). Antecedents of Learner Satisfaction toward E-learning. Journal of American Academy of Business, 11(2), 161-168.

Liang, J. C., \& Tsai, C. C. (2008). Internet self-efficacy and preferences toward constructivist Internetbased learning environments: A study of pre-school teachers in Taiwan. Educational Technology \& Society, 11(1), 226-237.

Liaw, S. S., \& Huang, H. M. (2013). Perceived satisfaction, perceived usefulness and interactive learning environments as predictors to self-regulation in e-learning environments. Computers \& Education. https://doi.org/10.1016/j.compedu.2012.07.015.

Lim, C. K. (2001). Computer self-efficacy, academic self-concept, and other predictors of satisfaction and future participation of adult distance learners. American Journal of Distance Education. https://doi. org/10.1080/08923640109527083.

Marinoni, G., Van't Land, H., \& Jensen, T. (2020). The Impact of COVID-19 on Higher Education Around the World IAU Global Survey Report. Retrieved from: https://www.iau-aiu.net/IMG/pdf/ iau_covid19_and_he_survey_report_final_may_2020.pdf. Accessed 20 June 2020.

Martin, F., Tutty, J. I., \& Su, Y. (2010). Influence of learning management systems self-efficacy on e-learning performance. Journal on School Educational Technology, 5(3), 26-35.

Matthieu, M. M., \& Ivanoff, A. (2006). Using stress, appraisal, and coping theories in clinical practice: Assessments of coping strategies after disasters. Brief Treatment and Crisis Intervention. https://doi. org/10.1093/brief-treatment/mhl009.

Moore, M. G. (1989). Three types of interactions. The American Journal of Distance Education, 3(2), 1-6.

Moore, M. G., \& Kearsley, G. (2005). Distance education: A systems view (2nd ed.). Wadsworth.

Muenks, K., Wigfield, A., Yang, J. S., \& O’Neal, C. R. (2017). How true is grit? Assessing its relations to high school and college students' personality characteristics, self-regulation, engagement, and achievement. Journal of Educational Psychology. https://doi.org/10.1037/edu0000153.

Nordstokke, D. W., \& Zumbo, B. D. (2010). A new nonparametric Levene Test for Equal Variances. Psicologica, 31(2), 401-430.

Nordstokke, D. W., Zumbo, B. D., Cairns, S. L., \& Saklofske, D. H. (2011). The operating characteristics of the nonparametric Levene test for equal variances with assessment and evaluation data. Practical Assessment, Research, and Evaluation,. https://doi.org/10.7275/5t99-zv93.

O'Connor, K. M., Arnold, J. A., \& Maurizio, A. M. (2010). The prospect of negotiating: Stress, cognitive appraisal, and performance. Journal of Experimental Social Psychology. https://doi.org/10.1016/j. jesp.2010.04.007.

O'Neill, M.A. \& Palmer, A. (2004). Importance-performance analysis: A useful tool for directing continuous quality improvement in higher education. Quality Assurance in Education. https://doi.org/ $10.1108 / 09684880410517423$

Palincsar, A. S. (1998). Social constructivist perspectives on teaching and learning. Annual Review of Psychology, 49(1), 345-375.

Peacock, E. J., \& Wong, P. T. (1990). The stress appraisal measure (SAM): A multidimensional approach to cognitive appraisal. Stress Medicine, 6(3), 227-236.

Reinhart, J., \& Schneider, P. (2001). Student satisfaction, self-efficacy, and the perception of the two-way audio/video distance learning environment: A preliminary examination. Quarterly Review of Distance Education, 2(4), 357-65.

Richardson, M., Abraham, C., \& Bond, R. (2012). Psychological correlates of university students' academic performance: a systematic review and meta-analysis. Psychological Bulletin. https://doi.org/ 10.1037/a0026838.

Şahin, I. (2007). Predicting Student Satisfaction in Distance Education and Learning Environments. Turkish Online Journal of Distance Education, 8(2), 113-119.

Schunk, D. H. (1989). Self-efficacy and achievement behaviors. Educational Psychology Review, 1(3), 173-208.

Shea, P., \& Bidjerano, T. (2010). Learning presence: Towards a theory of self-efficacy, self-regulation, and the development of a communities of inquiry in online and blended learning environments. Computers \& Education. https://doi.org/10.1016/j.compedu.2010.07.017.

Swan, K. (2001). Virtual interaction: Design factors affecting student satisfaction and perceived learning in asynchronous online courses. Distance Education. https://doi.org/10.1080/0158791010220208. 
Umbach, P. D., \& Porter, S. R. (2002). How do academic departments impact student satisfaction? Understanding the contextual effects of departments. Research in Higher Education, 43(2), 209-234.

UNESCO. (2020). COVID-19 educational disruption and response. Retrieved from https://en.unesco.org/ covid19/educationresponse. Accessed 20 June 2020.

Yilmaz, R. (2017). Exploring the role of e-learning readiness on student satisfaction and motivation in flipped classroom. Computers in Human Behavior. https://doi.org/10.1016/j.chb.2016.12.085.

Young, A., \& Norgard, C. (2006). Assessing the quality of online courses from the students' perspective. The Internet and Higher Education. https://doi.org/10.1016/j.iheduc.2006.03.001.

Yükseltürk, E., \& Yıldırım, Z. (2008). Investigation of interaction, online support, course structure and flexibility as the contributing factors to students' satisfaction in an online certificate program. Journal of Educational Technology \& Society, 11(4), 51-65.

Publisher's note Springer Nature remains neutral with regard to jurisdictional claims in published maps and institutional affiliations. 